\title{
The Genetic Analysis of Resistance to Benomyl in Neurospora crassa
}

\author{
By KATHLEEN BORCK * AND H. D. BRAYMER \\ Department of Microbiology, Louisiana State University, \\ Baton Rouge, Louisiana, 70803 , U.S.A.
}

(Received 8 May I974; revised 4 July I974)

SUMMARY

Mutants of Neurospora crassa resistant to the fungicide, methyl-I-(butylcarbamoyl)-benzimidazolecarbamate, were isolated following u.v. irradiation of conidia. Genetic analysis of 15 of the mutant strains revealed that resistance was due to a single allele averaging 2.9 map units right of $y l o-I, 17.9$ units right of tryp-2 and 32. I units left of chol-2 in linkage group VI. Tests of heterokaryons containing both resistant and sensitive alleles indicated that resistance is dominant. The mutants did not possess the same degree of tolerance to the fungicide.

\section{INTRODUCTION}

Within the last decade there has been increasing interest, both public and scientific, in the use of systemic agricultural fungicides. Methyl-I-(butylcarbamoyl)-benzimidazolecarbamate (benomyl) has shown particular promise due to its broad-spectrum antifungal activity and low mammalian toxicity. Benomyl is fungitoxic at very low concentrations and has therefore become the subject of several investigations concerning its mode of action (Clemons \& Sisler, 1971; Hammerschlag \& Sisler, 1972, 1973; Davidse, 1973).

One consideration in the understanding of fungicidal action is the development of resistant organisms. Spontaneous resistance to benomyl and related benzimidazole fungicides occurs in a number of phytopathogenic fungi (Dekker, 1972), and laboratory-induced mutations to benomyl resistance may be obtained with relative ease (Bartels-Schooley \& MacNeill, 1970; Hastie \& Georgopoulos, 1971 ; Fourcade \& Laville, 1973). The frequency with which resistant strains appear is undoubtedly a reflection of the number of mutations necessary to promote tolerance and the mutability of the genes responsible (Dekker, 1972). Resistance arising through mutations at a number of genetic loci may well be an indication that the toxicant interferes with cell biochemistry at more than one metabolic step.

Our studies (unpublished) on the inhibitory mechanisms of benomyl in a representative Ascomycete, Neurospora crassa, have included a genetic analysis of benomyl-resistant mutants with the idea that such investigations might provide additional information as to whether single- or multi-site inhibition is involved. It was also of interest to determine whether resistance is dominant or recessive and what levels of benomyl tolerance could be produced. Neurospora was particularly good experimental material, since the wild-type strain is so sensitive to benomyl that growth is completely inhibited by concentrations as low as 0.25 $\mu \mathrm{g} / \mathrm{ml}$ and the organism has been well characterized both biochemically and genetically.

\section{METHODS}

Strains. All strains of $N$. crassa utilized in this study are designated according to the gene symbols used by the Fungal Genetics Stock Center, (FGSC), Humboldt State College

* Present address: Department of Molecular Biology, University of Edinburgh, Edinburgh EH9 3JR. 
Foundation, Arcata, California, U.S.A. Benomyl-resistant mutants were induced in a histidine auxotroph, hist-I A (FGSC68I), and wild-type strain 74-OR8-Ia (FGSC988) was used in the initial cross with isolated mutants. Standard mating type testers were $f$ A (FGSCI 838) and fla (FGSCI690). Strains employed in mapping procedures included both mating types of alcoy (FGSC997 and FGSC998), tryp-I; ylo-I (FGSCI207 and FGSC1208) and tryp-2; ylo-I; chol-2 (FGSC209I and FGSC2092). All stock cultures were obtained from the FGSC with the exception of $f \mathrm{~A}$ and $f \mathrm{a}$ which were provided by Dr D. R. Parker, Stanford University, U.S.A. Conidia were preserved at $5{ }^{\circ} \mathrm{C}$ by the silica-gel technique of Perkins (1962).

Media. Stock cultures were maintained on slants containing Vogel's ( 1964) citrate minimal salts solution, $\mathrm{I} \cdot 5 \%$ sucrose and $\mathrm{I} \cdot 5 \%$ agar. When auxotrophic mutants were used, growth supplements were added as follows $(\mu \mathrm{g} / \mathrm{ml})$; histidine $\mathrm{HCl}, \mathrm{IO0}$; choline chloride, 30 ; indole, 20; and tryptophan, I 50. Medium for tryp-I mutants was enriched with indole, and tryp-2 mutants were grown on minimal medium plus tryptophan. All crosses were carried out on the medium recommended by Westergaard \& Mitchell (1947) with $2 \%$ sucrose and the required growth factors. Colonial growth of Neurospora was induced by the addition of $1 \%$ $(\mathrm{w} / \mathrm{v})$ sorbose, $0.025 \%$ glucose and $0.025 \%$ fructose to minimal medium containing histidine. Benomyl-resistant mutants were scored on minimal slants containing appropriate growth requirements and either 0.5 or $\mathrm{I} \cdot 0 \mu \mathrm{g}$ benomy $/ \mathrm{ml}$. Technical grade benomyl (E. I. duPont de Nemours and $\mathrm{Co}$.) was dissolved in $100 \%$ ethanol immediately before use and added to the autoclaved medium using standard aseptic procedures, the volume of benomyl added never exceeding $0 \cdot \mathrm{I} \%(\mathrm{v} / \mathrm{v})$ of the medium.

Isolation, selection and mapping of benomyl-resistant mutants. An aqueous suspension of conidia from 5-day-old cultures of hist- $I A$ was filtered through cheese cloth and the concentration adjusted to approximately $10^{7}$ conidia/ml. A thin layer of the suspension was poured into a sterile Petri dish and conidia were irradiated at $50 \%$ kill (I $25 \mathrm{~s}$ ) under a $30 \mathrm{~W}$ General Electric $\mathrm{G}_{30} \mathrm{~T} 8$ germicidal lamp at a distance of $15 \mathrm{~cm}$ from the light source. Benomylresistant colonies were selected after plating treated conidia on sorbose medium containing either 0.5 or $1.0 \mu \mathrm{g}$ benomyl $/ \mathrm{ml}$. To ensure that benomyl-resistant strains were homokaryotic for the mutant allele, resistant ascospores were selected after crossing resistant colonies to strain 74A. Methods for crossing and random ascospore isolation have been described by Perkins (1959). Fifteen out of a total of 4I resistant isolates were used for mapping (Perkins, Newmeyer, Taylor \& Bennett, 1969).

Resistance levels of mutants. Tolerance to various concentrations of benomyl was examined for all mutants used in mapping studies. Growth rates of each resistant strain were measured on benomyl medium by the method of Ryan, Beadle \& Tatum (1943), and average growth rates at each concentration of benomyl were computed from a plot of growth $(\mathrm{mm})$ versus time (days).

Formation of heterokaryons. From crosses between benomyl-resistant mutants and strains 2091 and 2092, recombinants were selected which exhibited either resistance or sensitivity and only one auxotrophic phenotype (e.g. either Tryp- or $\mathrm{Chol}^{-}$, but not both). Both cultures forming the heterokaryon were tested on minimal medium to ensure that tryp and chol mutations were non-leaky. Heterokaryons between recombinants were produced (Beadle \& Coonradt, 1944) possessing the benomyl-sensitive (ben-s) and benomyl-resistant (ben-r) alleles. They were tested for resistance by transfer to benomyl slants. Specific tolerance levels were determined for two of the heterokaryons using the procedures described above. 
(a)
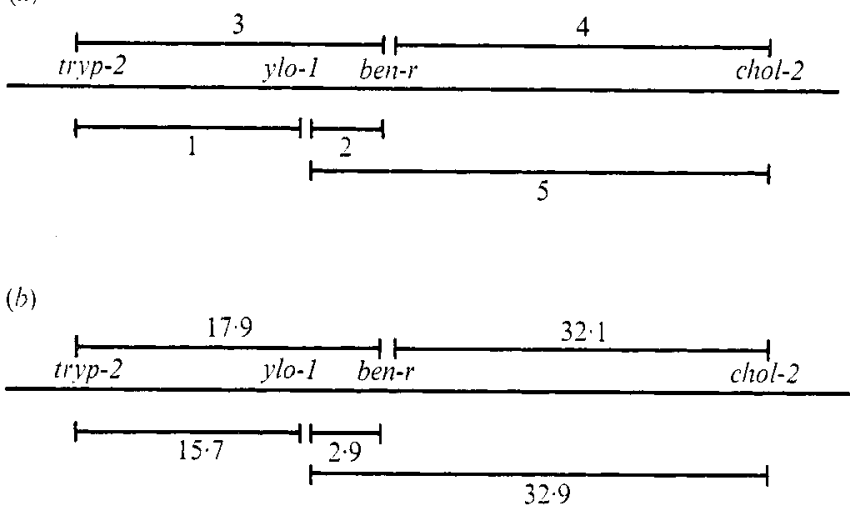

Fig. I (a). Partial map of linkage group VI showing only the markers utilized in mapping of the ben-r allele. Regions between markers are arbitrarily numbered and refer to those regions designated in Table I. (b) Map distances derived by calculation of mean values presented in Table $I$.

\section{RESULTS}

Genetic analysis of benomyl-resistant mutants. The 15 resistant isolates chosen for complete mapping procedures represented both mating types as well as $\mathrm{Hist}^{+}$or $\mathrm{Hist}^{-}$phenotypes. Eight of these mutants were crossed to suitable mating types of alcoy for preliminary linkage tests. In alcoy there are three reciprocal translocations with easily scorable markers near the interchange points, and the gene in question may therefore be placed in either of the linkage groups involved in the translocation according to its linkage to the marker. The marker for translocation between linkage groups I and II is al (albino); cot-I (colonial, temperature-sensitive) serves as a marker for IV:V translocation and $y l o-I$ (yellow) for a III: VI translocation. The data (not shown) from these crosses clearly demonstrated that benomyl resistance was linked to $y$ lo- $I$, e.g. all isolates having orange pigmentation were resistant and all yellow were sensitive. The resistant allele(s) could therefore be placed in linkage groups III, VI or both. Segregation of benomyl resistance relative to cot-I and $a l$ was approximately $50 \%$ in all cases.

The assignment of benomyl resistance to a site on linkage group VI was accomplished via a cross of mutants to strains $\mathrm{I} 207$ and $\mathrm{I} 208$, which carry the marker tryp-I on linkage group III and $y l o-I$ on linkage group VI. Phenotypic scoring of ascospores revealed close linkage of resistance to $y l o-I$, and in no instance was segregation of resistance paired with that of tryp-I. The localization of resistance on a single linkage group suggested that benomyl tolerance might be conferred by mutation at a single site. Therefore, the resistant allele in all I 5 mutants was mapped with respect to markers tryp-2, ylo-I and chol-2 in a cross with the triple mutant strains 209I and 2092.

Ascospores from each cross were scored for recombinations in regions I to 5, which are illustrated in Fig. I $(a)$. The results are presented in Table I and in Fig. I $(b)$, which gives the map units of each region as calculated by averaging the recombination frequencies given in the Table. The correlation of all map unit values for each region strongly implies that benomyl resistance is conferred by a single allelic mutation which maps approximately $2 \cdot 9$ units to the right of $y l o-I, 32 \cdot I$ units left of $c h o l-2$ and 17.9 units from tryp-2. Although the mean recombination frequencies in regions 4 and 5 were similar, the difference between frequencies in regions 3 and I suggests that ben-r is to the right of $y l o-I$.

Tolerance levels. Linear growth on solid medium in the presence of various concentrations 
Table $\mathrm{I}$. Recombination frequencies in regions $\mathrm{I}$ to 5 (see Fig. I a) as determined from crosses of benomyl-resistant strains with triple mutant strains 2091 and 2092

\begin{tabular}{|c|c|c|c|c|c|c|}
\hline \multirow{2}{*}{$\begin{array}{l}\text { Resistant } \\
\text { strains }\end{array}$} & \multicolumn{5}{|c|}{ Recombination $(\%)$ in region: } & \multirow{2}{*}{$\begin{array}{c}\text { No. } \\
\text { ascospores } \\
\text { analysed }\end{array}$} \\
\hline & I & 2 & 3 & 4 & 5 & \\
\hline $5 \mathrm{II}$ & I 5 & $4 \cdot 8$ & I8 & 39 & 39 & 124 \\
\hline 519 & 12 & $2 \cdot 9$ & I5 & 34 & 33 & 103 \\
\hline 526 & 17 & $3 \cdot I$ & 20 & 32 & 35 & 130 \\
\hline 5210 & I I & $4 \cdot 8$ & 16 & $3 I$ & $3 I$ & I 24 \\
\hline 557 & 19 & $3 \cdot 3$ & 22 & 26 & 27 & 90 \\
\hline 572 & 15 & $3 \cdot 2$ & 18 & 32 & 35 & 124 \\
\hline 586 & 25 & $\mathrm{I} \cdot 8$ & 24 & 33 & 35 & 114 \\
\hline 5810 & 12 & 3.5 & I5 & 29 & 32 & 113 \\
\hline 5102 & $2 I$ & $2 \cdot 4$ & 23 & 34 & 35 & I 27 \\
\hline 5107 & I4 & 3.0 & 18 & 26 & 27 & 132 \\
\hline 5128 & 19 & 3.0 & 18 & 32 & $3 I$ & 134 \\
\hline I I I & 14 & $2 \cdot 5$ & 15 & 30 & $3 I$ & I 19 \\
\hline 123 & 15 & $3 \cdot 8$ & 18 & 39 & 36 & 105 \\
\hline I 28 & 10 & 0.0 & 10 & 32 & 32 & II 4 \\
\hline 159 & 17 & $\mathrm{I} \cdot 8$ & 19 & 32 & 34 & I 12 \\
\hline $\begin{array}{l}\text { Mean* } \\
\text { Standard }\end{array}$ & $15 \cdot 7$ & $2 \cdot 9$ & $17 \cdot 9$ & $32 \cdot 1$ & $32 \cdot 9$ & \\
\hline error* & I.08 & 0.24 & 0.95 & 0.99 & 0.87 & \\
\hline
\end{tabular}

Table 2. Growth rates of wild-type Neurospora (74A) and benomyl-resistant mutants on solid medium containing various concentrations of benomyl

\begin{tabular}{|c|c|c|c|c|c|c|c|c|c|c|c|c|}
\hline \multirow{2}{*}{ Strain } & \multicolumn{12}{|c|}{ Growth rate ( $\mathrm{mm} /$ day) at concentrations of benomyl of $(\mu \mathrm{g} / \mathrm{ml}$ medium): } \\
\hline & 0 & O.I & 0.15 & 0.2 & 0.25 & 0.5 & $\mathrm{I} \cdot \mathrm{O}$ & $2 \cdot 0$ & 3.0 & 50 & $7 \cdot 0$ & $10 \cdot 0$ \\
\hline $74 \mathrm{~A}$ & 93 & 75 & 62 & 35 & 0 & 0 & - & - & - & - & - & - \\
\hline 5II & 92 & - & 一 & 100 & 一 & 95 & 95 & - & 80 & 62 & 42 & 30 \\
\hline 519 & 82 & - & - & - & - & 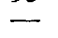 & 78 & - & 68 & 40 & 35 & 20 \\
\hline 526 & 100 & - & - & 96 & - & 96 & 85 & - & 55 & 38 & 0 & - \\
\hline 5210 & 30 & - & - & - & - & - & 25 & - & IO & 3 & 2 & 0 \\
\hline 557 & 65 & - & - & 60 & - & 55 & 35 & - & 0 & 0 & - & - \\
\hline 572 & 50 & - & - & - & - & $4 I$ & 40 & 31 & 0 & 0 & 0 & 0 \\
\hline 586 & 40 & - & - & - & - & 35 & 30 & 23 & 0 & 0 & 0 & 0 \\
\hline 5810 & 95 & - & - & 95 & - & 95 & 95 & - & 50 & 45 & 7 & 0 \\
\hline 5102 & 66 & - & - & - & - & - & 62 & 45 & 15 & 0 & 0 & 0 \\
\hline 5107 & 70 & - & - & - & - & 85 & 80 & 55 & - & - & - & - \\
\hline 5128 & 85 & - & - & - & - & - & 65 & - & 40 & 30 & II & 0 \\
\hline III I & 55 & - & - & - & - & - & 48 & 38 & 10 & 0 & - & - \\
\hline I 28 & 42 & - & - & - & - & - & 32 & - & - & - & - & 22 \\
\hline I 59 & 90 & - & - & - & - & - & 70 & 50 & 40 & 35 & 0 & 0 \\
\hline
\end{tabular}

of benomyl was used to estimate the sensitivities of mutants which had been mapped. This procedure was more desirable than measurements of dry weight from liquid cultures, primarily because our observations (unpublished) have shown cell wall synthesis continues in the presence of benomyl such that dry weight as an index of growth becomes inaccurate. Data presented in Table 2 demonstrates that some of the mutants were capable of growth in concentrations of benomyl nearly 100 times the levels inhibiting growth of wild-type Neurospora (74A). In all cases the growth rate on benomyl medium remained linear over a period of $96 \mathrm{~h}$, indicating that mutants were unable to recover from or adapt to the presence 
Table 3. Relative levels of resistance expressed by ben-r/ben-s heterokaryons of $N$. crassa

\begin{tabular}{|c|c|c|c|c|}
\hline \multirow[b]{2}{*}{$\begin{array}{l}\text { Strains paired } \\
\text { in heterokaryon }\end{array}$} & \multicolumn{2}{|c|}{ Characteristics of each strain } & \multicolumn{2}{|c|}{$\begin{array}{l}\text { Relative growth } \\
\text { in benomyl medium* }\end{array}$} \\
\hline & $\begin{array}{l}\text { Mating } \\
\text { type }\end{array}$ & Phenotype & $0.5 \mu \mathrm{g} / \mathrm{ml}$ & $\mathrm{I} \cdot \mathrm{o} \mu \mathrm{g} / \mathrm{ml}$ \\
\hline $\begin{array}{r}526,38 \\
5128,80\end{array}$ & $\begin{array}{l}\mathrm{a} \\
\mathrm{a}\end{array}$ & $\left.\begin{array}{l}\text { Ben-s, Tryp }{ }^{+}, \mathrm{Chol}^{-} \\
\text {Ben-r, Tryp } \\
-\mathrm{Chol}^{+}\end{array}\right\}$ & +++ & + \\
\hline $\begin{array}{l}511,70 \\
572,97\end{array}$ & $\begin{array}{l}\mathrm{A} \\
\mathrm{A}\end{array}$ & $\left.\begin{array}{l}\text { Ben-s, Tryp }{ }^{-}, \mathrm{Chol}^{+} \\
\text {Ben-r, Tryp }^{+}, \mathrm{Chol}^{-}\end{array}\right\}$ & +++ & ++ \\
\hline $\begin{array}{l}5 \mathrm{II}, 44 \\
5 \mathrm{II}, \mathrm{IO}\end{array}$ & $\begin{array}{l}\text { A } \\
\mathbf{A}\end{array}$ & $\begin{array}{l}\text { Ben-s, Tryp }- \text {, Chol }+ \\
\text { Ben-r, Tryp } \\
+\end{array}$ Chol- $\left.^{-}\right\}$ & +++ & + \\
\hline $\begin{array}{r}586,11 \\
5128,80\end{array}$ & $\begin{array}{l}\mathrm{a} \\
\mathrm{a}\end{array}$ & $\left.\begin{array}{l}\text { Ben-s, Tryp', } \text { Chol- }^{-} \\
\text {Ben-r, Tryp- } \text { Chol }^{+}\end{array}\right\}$ & +++ & $+t+$ \\
\hline $\begin{array}{r}159,97 \\
5107,1 \text { I }\end{array}$ & $\begin{array}{l}\text { A } \\
\text { A }\end{array}$ & $\left.\begin{array}{l}\text { Ben-s, Tryp }{ }^{+}, \mathrm{Chol}^{-} \\
\text {Ben-r, Tryp } \\
-\mathrm{Chol}^{+}\end{array}\right\}$ & +++ & + \\
\hline $\begin{array}{r}5107,5 \\
128,9\end{array}$ & $\begin{array}{l}\text { A } \\
\text { A }\end{array}$ & $\left.\begin{array}{l}\text { Ben-s, Tryp }{ }^{-}, \mathrm{Chol}^{+} \\
\text {Ben-r, Tryp }{ }^{+}, \mathrm{Chol}^{-}\end{array}\right\}$ & +++ & ++ \\
\hline
\end{tabular}

of the toxicant. The resistant strains did not exhibit the same growth rates or the same degree of tolerance to increases of benomyl concentration.

Heterokaryons. Tests for benomyl resistance among heterokaryons (Table 3) revealed that all seven were able to grow in the presence of the fungicide, so the mutations are dominant. Preliminary estimations of the growth rates exhibited by two of the heterokaryons at various levels of benomyl indicated complete dominance, i.e. although the growth rates of heterokaryons on benomyl medium were much slower than those of individual strains, the maximum tolerance levels were equal to those of the dominant member of the heterokaryon.

\section{DISCUSSION}

Genetic analysis of a number of benomyl-resistant mutants of $N$. crassa suggest that dominant mutations in a single gene are responsible for tolerance. The results are in contrast to those of Hastie \& Georgopoulos (I97I) who concluded that benomyl resistance in Aspergillus nidulans was due to mutation at either of two unlinked loci, ben-I or ben-2. Multiplegene resistance to actidione has been reported in Saccharomyces cerevisiae (Wilkie \& Lee, 1965; Brusick, 1972) and in N. crassa (Hsu, 1963); therefore it is conceivable that more than one gene for benomyl resistance could be found in Neurospora. Our selection and mapping procedures exclude the possibilities that additional dominant mutations at another site have taken place or that the isolates under investigation have all arisen from a single mutation early in the selection procedure.

It is possible that recessive mutations to benomyl resistance occur. In a multinucleate conidium, the presence of a recessive allele for resistance would go unnoticed. In our system, the isolation of a recessive allele for benomyl resistance would require that only the nucleus carrying the mutation survived the u.v. irradiation or that the mutation occurred in a mononucleate conidium. It is also conceivable that modifier genes exist, similar to those found for actidione resistance in $S$. cerevisiae (Wilkie \& Lee, 1965), which promote varying degrees of resistance, and the difference in tolerance levels observed among the mutants suggests that this may be so. 
The apparent lack of a multi-genic system for resistance and the extremely low levels of fungicide necessary to inhibit growth of wild-type Neurospora may indicate that benomyl has only a single enzymic site of inhibition. Biochemical studies of benomyl and related compounds, such as 2-methyl benzimidazolecarbamate and thiabendazole suggest that they have similar modes of action (Clemons \& Sisler, I971; Hammerschlag \& Sisler, 1972, 1973; Davidse, 1973) and cross-resistance to these fungicides has been reported in some organisms (Bartels-Schooley \& MacNeill, I97I ; Hastie \& Georgopoulos, I97I). Thus multiple resistance to benzimidazoles might result from mutation at a single locus. Such a finding would suggest these toxicants inhibit fungal growth by similar means.

This report is taken from a Ph.D. dissertation submitted by K. B. to Lousiana State University. K. B. was supported in part by USPHS Traineeship Grant No. GMoo692 and by an LSU Summer Fellowship. We are endebted to Ms Pamela Abraham for excellent technical assistance.

\section{REFERENCES}

Bartels-Schooley, J. \& MACNeill, B. H. (1970). The response of several mutants of Fusarium to benomyl and related fungicides. Phytopathology 6o, 57I (Abstract).

Bartels-Schooley, J. \& MacNeill, B. H. (1971). A comparison of the modes of action of three benzimidazoles. Phytopathology 6r, 816-819.

Beadle, G. W. \& CoOnRadt, V. L. (1944). Heterocaryosis in Neurospora crassa. Genetics 29, 29I-308.

Brusick, D. J. (1972). Induction of cycloheximide resistant mutants in Saccharomyces cerevisiae with $\mathrm{N}$ methyl- $N^{\prime}$-nitrosoguanidine and ICR-70. Journal of Bacteriology 109, I I 34-I I 38.

Clemons, G. P. \& Sisler, H. D. (1971). Localization of the site of action of a fungitoxic benomyl derivative. Pesticide Biochemistry and Physiology 1, 32-43.

Davidse, L. C. (1973). Antimitotic activity of methyl benzimidazol-2-yl carbamate (MBC) in Aspergillus nidulans. Pesticide Biochemistry and Physiology 3, 317-325.

DekKer, J. (1972). Resistance. In Systemic Fungicides, pp. 156-174. Edited by R. W. Marsh. London: Longman Group.

FourCADE, I. \& LAVILLE, E. (1973). Obtention in vitro de souches resistantes au Benomyl chez le Cercospora musae zimm. Fruits, Paris 28, 103-105.

HammerschlaG, R. S. \& Sisler, H. D. (I972). Differential action of benomyl and methyl-2-benzimidazolecarbamate (MBC) in Saccharomyces pastorianus. Pesticide Biochemistry and Physiology 2, I23-13I.

HammerschlaG, R. S. \& Sisler, H. D. (1973). Benomyl and methyl-2-benzimidazolecarbamate (MBC): biochemical, cytological and chemical aspects of toxicity to Ustilago maydis and Saccharomyces cerevisiae. Pesticide Biochemistry and Physiology 3, 42-54.

Hastie, A. C. \& Georgopoulos, S. G. (197I). Mutational resistance to fungitoxic benzimidazole derivatives in Aspergillus nidulans. Journal of General Microbiology 67, 37I-373.

Hsu, K. S. (1963). The genetic basis of actidione resistance in Neurospora. Journal of General Microbiology 32, 34I-347.

Perkins, D. D. (1959). New markers and multiple point linkage data in Neurospora. Genetics 44, I i 85-1 208.

Perkins, D. D. (1962). Preservation of Neurospora stock cultures with anhydrous silical gel. Canadian Journal of Microbiology 8, 59I-594.

Perkins, D. D., Newmeyer, D., Taylor, C. W. \& Bennett, D. C. (I969). New markers and map sequences in Neurospora crassa, with a description of mapping by duplication coverage, and of multiple translocation stocks for testing linkage. Genetica 40, 247-278.

Ryan, F. J., Beadle, G. W. \& TATum, E. L. (1943). The tube method of measuring growth rate of Neurospora. American Journal of Botany 30, 784-799.

Vogel, H. J. (1964). Distribution of lysine pathways among fungi: evolutionary implications. American Naturalist 98, 435-446.

WestergaArd, M. \& Mitchell, H. K. (1947). Neurospora. V. A synthetic medium favouring sexual reproduction. American Journal of Botany 34, 573-577.

WILKIE, D. \& LeE, B. K. (1965). Genetic analysis of actidione resistance in Saccharomyces cerevisiae. Genetical Research 6, I30-138. 